\title{
Relação entre uso e cobertura da terra e parâmetros biofísicos no Cerrado Brasileiro
}

\section{Relationship between land cover and biophysical parameters in the Brazilian Savana}

\author{
Alécio Perini Martins ${ }^{* 1} \bowtie(D$, Emerson Galvani² $₫$ (D) \\ 1 Unidade Acadêmica Especial de Estudos Geográficos, Universidade Federal de Jataí, Jataí, \\ Goiás, Brasil \\ 2Departamento de Geografia, Faculdade de Filosofia, Letras e Ciências Humanas, Universidade \\ de São Paulo, São Paulo, São Paulo, Brasil \\ E-mail: egalvani@usp.br \\ E-mail para correspondência: alecioperini@ufg.br
}

Recebido (Received): 14/03/2020 Aceito (Accepted):10/12/2020

Resumo: O uso e cobertura da terra é fundamental na regulação do ciclo da água, influenciando o processo de evapotranspiração. Mudanças nas categorias de uso vão interferir diretamente no saldo de radiação por meio da alteração de três parâmetros biofísicos: o albedo, o índice de vegetação e a temperatura de superfície. Neste sentido, a pesquisa objetiva avaliar a relação entre o uso e cobertura da terra e parâmetros biofísicos envolvidos na estimativa de fluxos de calor e evapotranspiração real. Estes parâmetros foram estimados por meio do SEBAL (Surface Energy Balance Algorithms for Land), modelo essencialmente matemático que necessita de poucos dados coletados em superfície para sua calibração. A área de estudo compreende sete bacias hidrográficas localizadas em áreas significativas do Sudoeste de Goiás e Noroeste de Mato Grosso do Sul, domínio do Cerrado, com grande diversidade de ocupação das terras, onde predominam as áreas de produção de grãos e pecuária de corte. A temperatura de superfície foi identificada como o parâmetro biofísico com maior correlação com o saldo de radiação, fluxos de calor e evapotranspiração, apresentando coeficientes de determinação superiores a 80\%. O albedo, apesar de apresentar coeficiente de determinação na faixa de $60 \%$, também mostrou-se como importante indicativo de mudanças ambientais com efeito direto sobre o ciclo da água. A análise estatística indica ainda que o modelo mostra-se eficaz para estimativa de evapotranspiração em grandes áreas, com diversidade de uso e poucos pontos de monitoramento em campo.

Palavras-chave: Mudanças ambientais; Albedo; Temperatura Superfícial; SEBAL.

Abstract: Land use and land cover is essential in regulating the water cycle and influences the evapotranspiration process. Land use and land cover changes will directly affect the balance of radiation by changing three biophysical parameters: albedo, NDVI and the surface temperature. This research aims at evaluating the relationship between land use and land cover and biophysical parameters involved in the estimation of heat flows and real evapotranspiration. These parameters were estimated using SEBAL (Surface Energy Balance Algorithms for Land), an essentially mathematical model that requires a few data collected on the surface for calibration. The study area comprises seven watersheds located in significant areas of the Southwest of Goiás State and Northwest of Mato Grosso do Sul State, Cerrado biome, with great diversity of land cover where areas of soy and corn production and livestock predominate. The surface temperature was identified as the biophysical parameter with the highest correlation with the balance of radiation, heat flows and evapotranspiration, with determination coefficients greater than $80 \%$. The albedo, despite having a coefficient of determination in the range of 60\%, also proved to be an important indicator of environmental changes with direct effects on the water cycle. The statistics also indicates that SEBAL is effective for estimating evapotranspiration in large areas, with diversity of land cover and few monitoring points.

Keywords: Environmental changes; Albedo; Surface temperature; SEBAL. 


\section{Introdução}

Considerando as alterações na paisagem, bem como o aperfeiçoamento de técnicas de estudo e modelos de previsão de cenários de mudanças ambientais, a Geografia tem exercido papel importante por ser uma ciência que apresenta uma visão ampla dos fenômenos, permitindo que atividades de planejamento e gestão sejam mais eficientes, especialmente ao utilizar ferramentas de análise espacial aplicadas a imagens de sensoriamento remoto em sistemas de informação geográfica.

Assim, o uso de modelos matemáticos, baseados em informações de imagens orbitais e dados coletados em superfície, aliados aos conhecimentos geográficos sobre a dinâmica das paisagens, se mostra como alternativa viável para realizar estudos e monitoramentos em áreas com grande extensão territorial, de difícil acesso e/ou com escassez de informações.

Atualmente, o Instituto Nacional de Pesquisas Espaciais (INPE), assim como outros órgãos públicos, disponibilizam imagens orbitais de média e baixa resolução espacial gratuitamente, o que tem permitido ganhos qualitativos e quantitativos em pesquisas e atividades de monitoramento e gestão instrumentados por Sensoriamento Remoto. Este incremento tecnológico permitiu o estudo integrado dos grandes domínios morfoclimáticos brasileiros, como, por exemplo, por meio do projeto MapBiomas, iniciativa multiinstitucional envolvendo universidades, ONGs e empresas de tecnologia que realizam o mapeamento anual do uso e cobertura da terra no Brasil (http://mapbiomas.org/), e do PRODES (Programa de Monitoramento da Floresta Amazônica Brasileira por Satélite), iniciativa do INPE que fornece informações anuais sobre a taxa de desmatamento na Amazônia e no Cerrado a partir de informações de satélite (http://terrabrasilis.dpi.inpe.br/app/map/deforestation).

No caso do Cerrado Brasileiro, estas iniciativas são fundamentais por permitirem o acompanhamento de um domínio que está no centro de expansão da fronteira agrícola nacional desde a década de 1970, com altas taxas de desmatamento anuais. Conforme Ab'Saber (2003, p.115-119), o domínio do Cerrado "constitui-se em um espaço físico, ecológico e biótico, de primeira ordem de grandeza, possuindo de 1,7 a 1,9 milhões de quilômetros quadrados de extensão", com predomínio de decomposição química das rochas cristalinas, de latossolos, convexização discreta do relevo e padrões de drenagem que variam de subparalelo a ligeiramente dendrítico.

As características naturais deste ambiente, sobretudo o relevo plano/suave ondulado, solos profundos e bem drenados e a disponibilidade hídrica em abundância, além da proximidade com as maiores regiões consumidoras do Centro-Sul do Brasil, contribuíram para que o Cerrado se tornasse área prioritária de atração de políticas de governo e migrantes. Conforme Pessôa (1988), a partir da década de 1970 o Cerrado tornou-se um dos principais focos de programas de desenvolvimento e expansão da agropecuária no interior do país com a criação da Centro de Pesquisa Agropecuária do Cerrado CPAC/EMBRAPA e o lançamento de programas de cooperação internacional como o PRODECER (Programa de Cooperação Nipo-Brasileiro para o Desenvolvimento Agrícola dos Cerrados) e o POLOCENTRO (Programa de Desenvolvimento da Região Centro-Oeste).

De acordo com o MapBiomas (2019), entre os anos de 1985 e 2018 o Cerrado perdeu aproximadamente $21 \%$ de sua cobertura original, que já demonstrava intensificação de desmatamento desde a década de 1950, tendo as áreas de agropecuária um incremento de 50\%. Dados do PRODES (2019) apontam que, entre os anos de 2001 e 2019, o Estado de Goiás perdeu uma área de 45.137,03 km² de Cerrado, o que corresponde a $13,3 \%$ do território estadual.

Martins et al. (2016) apontam que para a região Sudoeste de Goiás, entre os anos de 1985 e 2015, as áreas com remanescente de vegetação decresceram de $40,1 \%$ para $29,1 \%$, enquanto a agropecuária salta de um percentual de 57,3\% em 1985 para 68,3\% em 2015 com tendência de crescimento a partir da instalação de usinas sucroalcooleiras na região.

Todo esse processo de mudança nas relações do uso e cobertura da terra apresentam efeitos diretos sobre o ciclo da água, já que são alterados parâmetros biofísicos que atuam no balanço de radiação na superfície e, consequentemente, nos fluxos de calor e evapotranspiração. Definida como a combinação entre os processos de evaporação da água pela superfície e da transpiração dos seres vivos, a evapotranspiração constitui parte significativa do ciclo hidrológico representando o "retorno" da água para a atmosfera (ALLEN et al. 1998). Ainda conforme os autores, a distinção entre as frações de evaporação e transpiração é complexa por ocorrem simultaneamente, sendo a evaporação de um solo cultivado determinada principalmente pela fração de radiação solar que atinge a superfície do solo. Assim, essa fração diminui ao longo do período de crescimento da cultura com o aumento da área de solo sombreada. 
Allen et al. (1998) destacam ainda que os principais fatores que atuam neste processo são: os parâmetros meteorológicos, principalmente a radiação solar, temperatura e umidade do ar e velocidade dos ventos (poder evaporante); as características das culturas/vegetação, como tipo de cultivo, variedades e estágio de desenvolvimento, altura das plantas, cobertura do solo e enraizamento; e as condições ambientais, com destaque para teor de água, porosidade, fertilidade e salinidade do solo, cobertura, manejo e densidade das plantas.

Nota-se que o uso e cobertura da terra é fator fundamental na regulação do ciclo da água, visto que pode influenciar tanto nos processos de evapotranspiração quanto na infiltração, escoamento e armazenamento da água no solo. Assim, mudanças nas classes de uso e cobertura da terra vão interferir diretamente no saldo de radiação por meio da alteração de três parâmetros biofísicos principais: o albedo, o NDVI (Índice de Vegetação por Diferença Normalizada) e a temperatura de superfície.

O albedo da superfície é definido como a razão entre a radiação refletida pela superfície e a radiação incidente sobre esta superfície, variando de acordo com as características físico-químicas e com o ângulo de incidência da radiação (NICÁCIO, 2008). Ainda segundo a autora, atividades humanas como desflorestamento, agricultura e urbanização são os principais fatores que promovem alteração do albedo, com efeitos diretos sobre o balanço de energia na superfície e, por sua vez, variações no micro ou macroclima.

Ming e Liu (2000), em mapeamento realizado para o Estado de São Paulo a partir de imagens AVHRR/NOAA destacaram que para esta área de estudo nas condições analisadas valores de albedo inferiores a 0,10 correspondem à corpos hídricos, entre 0,10 e 0,15 à vegetação intensa e de 0,15 a 0,25 à vegetação rasteira, pastagens e cultivos agrícolas. Valores entre 0,25 e 0,40 são típicos de áreas urbanas e com solo descoberto e regiões secas, enquanto que valores superiores a 0,40 indicam áreas com cobertura de nuvens. Visto que, quanto maior o albedo menor o saldo de radiação e, consequentemente, menor a evapotranspiração, a conversão de áreas vegetadas em atividades agropecuárias reduzem significativamente os valores de evapotranspiração real em superfície.

Com relação à temperatura de superfície, Mendonça et al. (2009, p.294) argumentam que o conhecimento da oscilação da temperatura é fundamental para regiões e épocas do ano nas quais sua variação possa inibir ou prejudicar o sistema radicular das culturas. No Cerrado esta observação é fundamental considerando a sazonalidade do clima, com estações secas que variam de 5 a 7 meses, se estendendo de maio a setembro (MARIANO, 2005). Os valores de temperatura de superfície registrados sempre serão superiores aos valores de temperatura do ar mensurados por instrumentos, visto que a superfície está diretamente exposta aos efeitos da radiação solar, sendo que a transformação em calor depende do material que compõe cada superfície.

O Índice de Vegetação por Diferença Normalizada (NDVI), assim como suas variações como o SAVI (Índice de Vegetação Ajustado ao Solo), corresponde ao índice mais utilizado para análises sobre a cobertura vegetal em diferentes escalas, sendo gerado pela diferença entre a reflectância no canal do infravermelho próximo e a reflectância no canal do vermelho. $\mathrm{O}$ resultado desta diferença varia de $-1 \mathrm{a}+1 \mathrm{e}$, quanto maior $\mathrm{o}$ valor do índice, maior a presença de vegetação (MOREIRA et al., 2010).

Ainda conforme Moreira et al. (2010), o uso de índices de vegetação como parâmetro biofísico de culturas agrícolas apresenta duas grandes vantagens: reduzir a dimensão das informações multiespectrais, minimizando o impacto das condições de iluminação e visada; e fornecer um número altamente correlacionado aos parâmetros agronômicos.

Além disso estes valores são fundamentais, em conjunto com o Índice de Área Foliar (IAF), para calcular a emissividade da superfície e a rugosidade do terreno que, respectivamente, serão utilizados na correção dos valores de temperatura de superfície e na estimativa do fluxo de calor sensível. Allen et al. (2002) conceituam o IAF como um parâmetro biofísico definido pela razão entre a área foliar de uma vegetação por unidade de área utilizada por essa vegetação, indicando a biomassa em cada pixel da imagem.

Para estimar estas variáveis, a criação, adaptação e/ou adoção de modelos é importante sobretudo em áreas com grande extensão territorial, áreas com cobertura insuficiente de estações climatológicas e meteorológicas, áreas de difícil acesso ou que apresentam grandes dificuldades e/ou custos de coletas de dados em campo. O SEBAL (Surface Energy Balance Algorithms for Land), desenvolvido por Bastiaanssen (1995), é um dos mais completos modelos para estudos de fluxo de calor na superfície com o uso de imagens de satélite e algumas informações climatológicas, como temperatura do ar e velocidade dos ventos.

A vantagem do modelo SEBAL para estimativa de fluxos de calor na superfície e evapotranspiração real é que os componentes do cálculo do saldo de radiação podem ser mensurados separadamente, permitindo 
uma estimativa mais precisa. Outra vantagem é que ele necessita de poucas informações coletadas em campo, podendo ser aplicado em grandes extensões de terra. A escala dos resultados vai estar relacionada ao tamanho do pixel da imagem utilizada, sendo que para estudos realizados a partir de imagens OLI (Operational Land Imager) e TIRS (Thermal Infrared Sensor) do satélite Landsat-8 a escala de trabalho é de $1: 150.000$.

Frente ao exposto, este artigo representa parte de uma pesquisa de pós-doutorado desenvolvida em sete bacias hidrográficas do Cerrado Brasileiro com a finalidade de adaptar o modelo SEBAL para estimativa de saldo de radiação, fluxos de calor e evapotranspiração real a partir de imagens do satélite Landsat-8 para o período de outubro de 2018 a setembro de 2019, além de avaliar o desempenho do modelo para estimativa de vazão por balanço hídrico simplificado. Especificamente neste artigo, objetivou-se avaliar a relação entre as características do uso e cobertura da terra e os valores calculados para parâmetros biofísicos diretamente envolvidos na estimativa de fluxos de calor e evapotranspiração real por meio de técnicas de sensoriamento remoto, indicando possíveis efeitos das mudanças ambientais sobre o clima em escalas local e regional.

\section{2. Área de estudo}

O estudo considerou áreas representativas do Cerrado Brasileiro no sudoeste do Estado de Goiás e nordeste do Estado de Mato Grosso do Sul (Figura 1), com diversidade de ambientes naturais e antrópicos e características climáticas similares. De forma geral, a região caracteriza-se por relevos planos/suave ondulados, recobertos predominantemente por latossolos. A agropecuária destaca-se na paisagem, entremeada por remanescentes de feições de Cerrado e formações florestais. Adotou-se como recorte temporal o ano hidrológico de 01/10/2018 a 30/09/2019.

Foram selecionadas sete bacias hidrográficas ou trechos de bacias pertencentes ao Cerrado brasileiro, sendo elas: Bacia do Rio Formoso, com $1.532 \mathrm{~km}^{2}$ de área, localizada no extremo sudoeste do estado de Goiás e com mais de $40 \%$ do território representado pelo Parque Nacional das Emas; Alto curso da Bacia do Rio Sucuriú (3.775 km²), na região nordeste de Mato Grosso do Sul, com grande diversidade de usos agropecuários e presença de extensas áreas de pastagens degradadas sobre solos arenosos; Alto e médio cursos das bacias dos rios Doce $\left(2.015 \mathrm{~km}^{2}\right)$, Monte Alegre $\left(809 \mathrm{~km}^{2}\right)$, Verdão $\left(1.015 \mathrm{~km}^{2}\right)$ e Verdinho $\left(1.668 \mathrm{~km}^{2}\right)$, entre os municípios de Jataí, Rio Verde e Montividiu no Sudoeste de Goiás, com grande diversidade de áreas agropecuárias, cultivo de cana-de-açúcar e agricultura irrigada por pivô central e reduzidas áreas de vegetação remanescente; Bacia do Rio Bonito $\left(2.015 \mathrm{~km}^{2}\right)$, nos municípios de Caiapônia, Palestina de Goiás e Arenópolis, constituindo uma área com diversificação de uso e desmatamento relativamente recentes, em região de expansão da fronteira agrícola goiana.

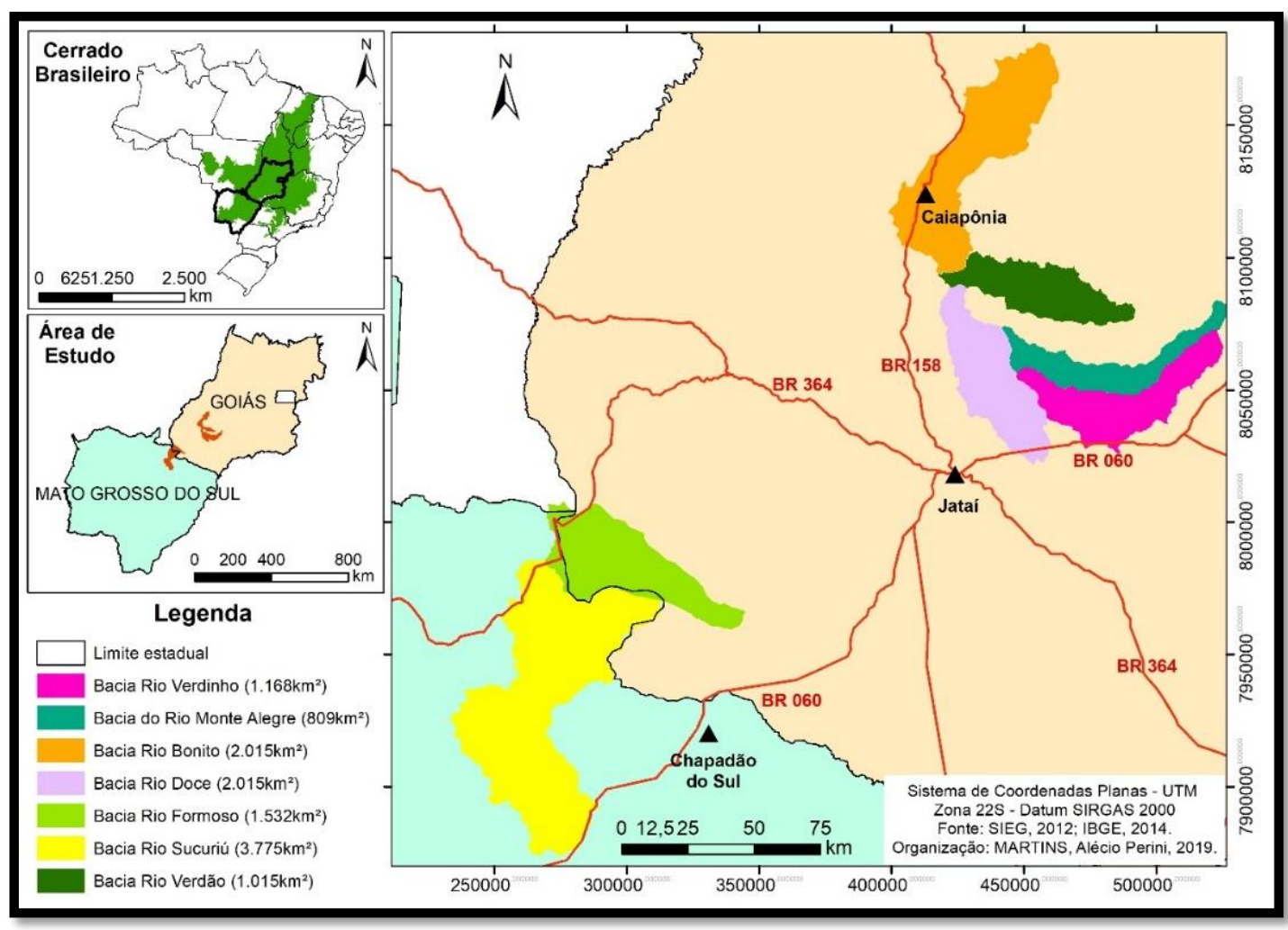

Figura 1: Localização da área de estudo. Organização: Dos autores, 2019. 
O clima da região se caracteriza como Aw (tropical quente em todas as estações do ano) de acordo com a classificação de Köppen, com temperatura média mensal superior a $18^{\circ} \mathrm{C}$ e inverno seco (DUBREUIL et al., 2018). Silva (2018) destaca que as precipitações no Cerrado diminuem no sentido oeste-leste, estando Goiás em uma faixa de precipitação média entre $1400 \mathrm{~mm}$ e $1600 \mathrm{~mm}$, apresentando totais de até $1800 \mathrm{~mm} \mathrm{em}$ porções isoladas do centro-sudoeste do Estado.

\section{Procedimentos}

\subsection{Bases de dados e análise estatística}

Inicialmente, foram identificadas três estações meteorológicas do INMET na região para calibração e validação do modelo: Jataí (GO), Caiapônia (GO) e Chapadão do Sul (MS). Como apoio, foram utilizados dados da Estação Convencional do INMET instalada em Jataí. As informações necessárias para calibração do modelo são: temperatura do ar média, máxima e mínima $\left({ }^{\circ} \mathrm{C}\right)$; umidade relativa do ar máxima e mínima $(\%)$; pressão atmosférica $(\mathrm{hPa})$; velocidade dos ventos $(\mathrm{m} / \mathrm{s})$; precipitação $(\mathrm{mm})$ e radiação $\left(\mathrm{W} / \mathrm{m}^{2}\right)$.

Os dados de precipitação mensal foram obtidos junto aos postos pluviométricos da Agência Nacional de Águas localizados nos municípios de Jataí, Rio Verde, Montividiu, Caiapônia, Arenópolis, Serranópolis, Aporé e Chapadão do Céu (em Goiás), e Chapadão do Sul, Cassilândia e Costa Rica (em Mato Grosso do Sul).

O banco de imagens foi composto por imagens de satélite (Landsat-8, sensores OLI e TIRS) e de radar (SRTM). As imagens OLI/Landsat-8 e SRTM apresentam resolução espacial de 30m e as do sensor TIRS de $100 \mathrm{~m}$, com reamostragem para $30 \mathrm{~m}$. Foram selecionadas 26 cenas Landsat- 8 em datas onde a cobertura de nuvens foi interior a $10 \%$ da cena, conforme a Tabela 1.

Tabela 1: Cenas Landsat-8 utilizadas na pesquisa.

\begin{tabular}{cc}
\hline Órbita/Ponto - Landsat-8 & \multicolumn{1}{c}{ Datas } \\
\hline \multirow{2}{*}{$223 / 72$} & $22 / 05 / 2018,10 / 08 / 2018,27 / 09 / 2018,16 / 12 / 2018,02 / 02 / 2019,26 / 06 / 2019$, \\
& $12 / 07 / 2019,28 / 07 / 2019$ \\
$223 / 73$ & $22 / 05 / 2018,25 / 07 / 2018,10 / 08 / 2018,11 / 09 / 2018,16 / 12 / 2018,06 / 03 / 2019$, \\
& $09 / 05 / 2019,26 / 06 / 2019,12 / 07 / 2019,28 / 07 / 2019$ \\
$224 / 73$ & $30 / 06 / 2018,08 / 01 / 2019,29 / 03 / 2019,09 / 05 / 2019,16 / 05 / 2019,01 / 06 / 2019$, \\
& $19 / 07 / 2019,05 / 09 / 2019$ \\
\hline
\end{tabular}

Organização: dos autores, 2019.

As imagens Landsat- 8 foram utilizadas para classificação de uso e cobertura da terra (bandas 6, 5 e 4 em composição RGB), para estimativa de albedo (bandas 2, 3, 4, 5, 6 e 7), NDVI, SAVI e IAF (bandas 4 e 5). As imagens SRTM foram utilizadas para a estimativa da transmissividade para cada pixel, parâmetro fundamental ao cálculo de albedo de superfície.

Inicialmente, procedeu-se com a correção radiométrica de cada banda a partir dos cálculos de Radiância e Reflectância conforme descrito por Ariza (2013). Os cálculos relativos ao ângulo de incidência da radiação, distância terra-sol, radiação solar no topo da atmosfera, refletância corrigida e transmissividade atmosférica seguiram os parâmetros do modelo METRIC (Satellite-Based Energy Balance for Mapping Evapotranspiration with Internalized Calibration) descritos por Allen et al. (2007).

As variáveis estimadas em 26 cenas do satélite Landsat-8 (albedo, NDVI, temperatura de superfície, saldo de radiação, fluxos de calor no solo, calor sensível e calor latente e evapotranspiração instantânea e diária) passaram por análise estatística descritiva, com geração de médias e identificação de valores máximos, mínimos, desvios padrão e variância. Em um segundo momento, identificou-se a Correlação de Pearson (r) e o coeficiente de determinação $\left(\mathrm{r}^{2}\right)$ entre os valores médios de cada variável para cada classe de uso e cobertura da terra (22 pares de valores médios, considerando 11 classes de uso e cobertura da terra).

A validação foi feita a partir de análise pareada (Teste $\mathrm{T}$ de student para comparação de médias) para variáveis independentes com nível de significância de $5 \%(\alpha=0,05)$. Após a identificação das variáveis $p$ (probabilidade de erro ao rejeitar a hipótese de nulidade) e T crítico (identificado com limiar de $\pm 2,086$ para 20 graus de liberdade), calculou-se a significância do coeficiente de correlação de Pearson (t) entre os pares de variáveis (ROGERSON, 2012). Todas as etapas da pesquisa foram desenvolvidas no software ArcGIS 10.6.1® e no Microsoft Excel 2013 ®. 


\subsection{Implementação do SEBAL}

A implementação do SEBAL ocorreu de acordo com o fluxograma descrito na Figura 2, cujas etapas e equações foram descritas por Allen et al. (2002). Deve-se ter atenção especial com a estimativa do fluxo de calor sensível, que precisa ser realizado quantas vezes forem necessárias até estabilizar os valores de resistência aerodinâmica (Rah). No caso desta pesquisa a estabilização ocorreu, em média, após o $60^{\circ}$ cálculo de Rah.

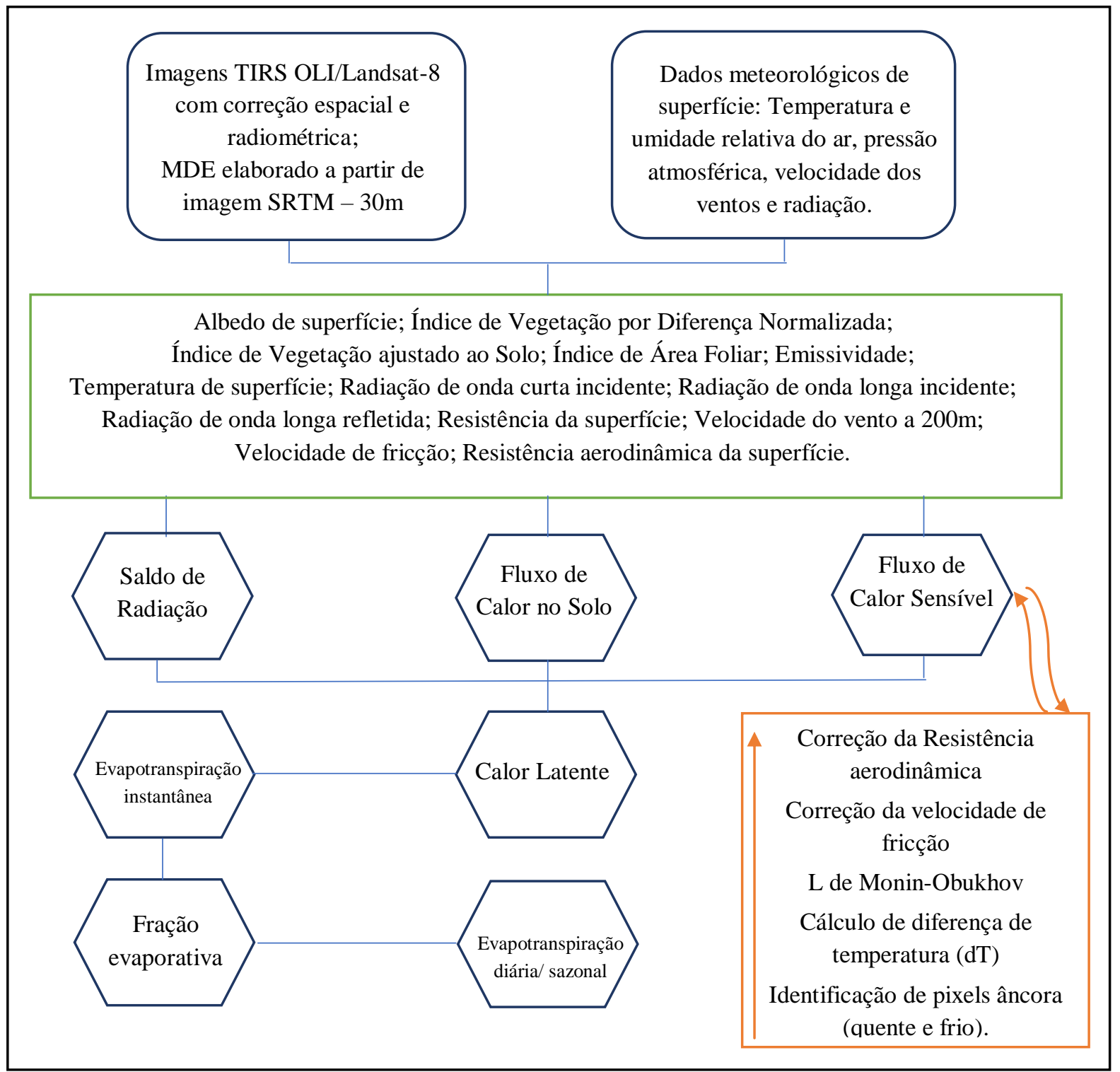

Figura 2: Fluxograma de implementação do modelo SEBAL. Adaptado de: Allen et al., 2002.

Para o cálculo da Evapotranspiração de Referência, utilizou-se a equação de Penman -Monteith descrita por Allen et al. (1998) (Equação 1).

$$
\mathrm{ET}_{0}=\frac{0.408 \Delta\left(R_{\mathrm{n}}-G\right)+\gamma \frac{900}{T+273} \mathrm{U}_{2}\left(\mathrm{e}_{\mathrm{s}}-\mathrm{e}_{\mathrm{a}}\right)}{\Delta+\gamma\left(1+0.34 \mathrm{U}_{2}\right)}
$$

Onde ETo é a evapotranspiração de referência ( $\mathrm{mm} / \mathrm{dia})$ calculada para o pixel onde localiza-se a estação automática do INMET; $\Delta$ a declividade da curva de pressão de vapor $\left(\mathrm{kPa}^{\circ} \mathrm{C}^{-1}\right) ; \mathrm{Rn}$ o saldo de radiação $\left(\mathrm{MJ} / \mathrm{m}^{2} / \mathrm{dia}\right) \mathrm{G}$ o fluxo de calor no solo $\left(\mathrm{MJ} / \mathrm{m}^{2} / \mathrm{dia}\right) ; \gamma$ a constante psicrométrica $\left(\mathrm{kPa}^{\circ} \mathrm{C}^{-1}\right) ; \mathrm{T}$ a temperatura do ar a $2 \mathrm{~m}\left({ }^{\circ} \mathrm{C}\right) ; \mathrm{U}_{2}$ a velocidade dos ventos a $2 \mathrm{~m}(\mathrm{~m} / \mathrm{s}) ; \mathrm{e}_{\mathrm{s}}$ a pressão do vapor saturado $(\mathrm{kPa}) ; \mathrm{e}_{\mathrm{a}}$ a pressão atual de vapor $(\mathrm{kPa})$. 
A evapotranspiração real instantânea (horária) foi calculada pixel a pixel, considerando tanto condições ideais, quanto de saturação ou restrição hídrica, a partir do saldo de calor latente $(\lambda E T)$ e o calor latente de evaporação ( $\lambda$ ), conforme Equações 2 e 3, descritas por Allen et al. (2007).

$$
E T h=3600 * \lambda \mathrm{ET} / \lambda
$$

Onde $\lambda$ corresponde ao calor latente de evaporação (Equação 3, dada em J/kg e descrita por HARRISSON, 1963, citado por ALLEN et al. 1998) e 3600 é o valor de conversão de segundos para horas (BASTIAANSSEN et al., 1998; NICÁCIO, 2008).

$$
\lambda=[2,501-0,00236 *(\mathrm{Ts}-273,16)] * 10^{6}
$$

Para estimar a evapotranspiração diária (Equação 4) e mensal/sazonal (Equação 5) é necessário calcular os valores de referência (ETo) para 24 horas e para o período, além de um componente conhecido como Fração Evaporativa, que é definida como a razão entre a evapotranspiração instantânea (ETh) e a evapotranspiração de referência (ETo). De acordo com Allen et al. (2002), os valores da fração evaporativa $(\mathrm{ETrF})$ são semelhantes ao coeficiente da cultura $(\mathrm{kc})$, variando de 0 a 1 e, ocasionalmente, atingindo valores superiores a 1 quando ETh for significativamente superior à ETo, como em corpos hídricos e áreas com vegetação arbórea muito densa.

$$
E T 24=E T r F * E T o 24
$$

Onde ETo24 (mm/dia) é o acumulado de ETo em 24 horas para o dia de obtenção da imagem, calculado a partir da soma dos valores de ETo horários ao longo do dia.

$$
\text { ETperiodo }=\text { ETrFperiod } * \sum_{1}^{n} \text { ETo24 }
$$

\subsection{Mapeamento de Uso e cobertura da terra}

Para o mapeamento das classes de uso e cobertura da terra selecionou-se duas imagens OLI/Landsat-8 sem cobertura de nuvens para cada uma das órbitas/ponto utilizadas no estudo: a) Para as órbitas/ponto 223/72 e 223/73 imagens dos dias 02/02/2019 (verão) e 26/06/2019 (inverno); b) Para a órbita/ponto 224/73 imagens do dia 08/01/2019 (verão) e 19/07/2019 (inverno). São necessárias imagens de períodos diferentes considerando a sazonalidade da região, sendo preciso identificar os diferentes tipos de cultivo (grãos, canade-açúcar e áreas irrigadas).

Inicialmente, gerou-se a composição colorida considerando as bandas 4,5 e 6 do OLI/Landsat-8 e posterior fusão com a banda 8 (pancromática com 15 metros de resolução espacial) para geração de composição colorida com resolução reamostrada para 15 metros. Em seguida, as cenas foram recortadas para as áreas das 07 bacias hidrográficas em estudo. Embora já apresentem georreferenciamento, este foi conferido e corrigido a partir da malha viária e das redes de drenagem em escala de 1:100.000 disponibilizadas pelo IBGE. As imagens de satélite foram obtidas gratuitamente na página do Serviço Geológico dos Estados Unidos (USGS/Earth Explorer) e processadas no software ArcGIS 10.6.1 ®.

A classificação das imagens recortadas para as bacias foi realizada de forma supervisionada, com a criação de 50 amostras (polígonos) de cada uma das classes: a) Agricultura (cana); b) Agricultura (grãos); c) Agricultura irrigada; d) Água; e) Área úmida; f) Cerrado; g) Cerradão/Formações florestais; h) Pastagem; i) Pastagem degradada; j) Silvicultura; k) Solo descoberto/ área urbana/ estradas pavimentadas. Foi aplicado o classificador Interactive Supervised Classification. As imagens temáticas foram convertidas para formato de polígono e passaram por correção de erros por interpretação visual. Validou-se o mapeamento por tabulação cruzada com aplicação do Coeficiente Kappa (COHEN, 1960; LANDIS; KOCH, 1977; FIGUEIREDO; VIEIRA, 2007), com nível de acerto de $90 \%$.

O mapa de uso e cobertura da terra de cada uma das bacias hidrográficas foi convertido novamente em formato raster, com geração de 550 pontos aleatórios de assinatura (50 pontos para cada classe) pela ferramenta Spatial Analyst Tools - Multivariate - Create Signatures. Estas amostras foram utilizadas para tabulação cruzada com as variáveis obtidas nas diversas etapas de implementação do SEBAL por meio da ferramenta Zonal Statistics as a Table, onde foram calculados os valores médios, máximos, mínimos e desvios padrão de cada grupo de amostras. 


\section{Resultados e discussão}

Conforme observado na Tabela 2, predominam na região os usos agropecuários, com destaque para a agricultura de grãos e a pecuária de corte (representada pelas áreas de pastagem e pastagem degradada na Tabela 2), presentes em todas as bacias. As áreas úmidas foram identificadas nas bacias dos Rios Formoso e Sucuriú, sobretudo em áreas de nascentes, mas também foram identificadas na órbita/ponto 223/72.

Tabela 2: Uso e cobertura da terra $(\%)-2019$.

\begin{tabular}{|c|c|c|c|c|c|c|c|}
\hline Categorias & $\begin{array}{c}\text { Rio } \\
\text { Bonito } \\
\left(2015 \mathrm{~km}^{2}\right) \\
\end{array}$ & $\begin{array}{c}\text { Rio } \\
\text { Formoso } \\
\left(1532 \mathrm{~km}^{2}\right) \\
\end{array}$ & $\begin{array}{c}\text { Rio } \\
\text { Sucuriú } \\
\left(3775 \mathrm{~km}^{2}\right) \\
\end{array}$ & $\begin{array}{l}\text { Rio Doce } \\
\left(2015 \mathrm{~km}^{2}\right)\end{array}$ & $\begin{array}{c}\text { Rio } \\
\text { Monte Alegre } \\
\left(809 \mathrm{~km}^{2}\right) \\
\end{array}$ & $\begin{array}{c}\text { Rio } \\
\text { Verdinho } \\
\left(1168 \mathrm{~km}^{2}\right) \\
\end{array}$ & $\begin{array}{c}\text { Rio } \\
\text { Verdão } \\
\left(1015 \mathrm{~km}^{2}\right) \\
\end{array}$ \\
\hline $\begin{array}{l}\text { Agricultura } \\
\text { (cana) }\end{array}$ & - & 2,8 & 10,0 & 24,4 & - & - & - \\
\hline $\begin{array}{l}\text { Agricultura } \\
\text { (grãos) }\end{array}$ & 11,8 & 33,0 & 19,1 & 42,2 & 62,0 & 52,9 & 69,7 \\
\hline $\begin{array}{l}\text { Agricultura } \\
\text { irrigada }\end{array}$ & - & - & - & - & 1,7 & 0,9 & 2,6 \\
\hline Água & 0,8 & 0,1 & 0,3 & 0,2 & 0,2 & 0,2 & 0,1 \\
\hline Área úmida & - & 1,9 & 1,8 & - & - & - & - \\
\hline $\begin{array}{l}\text { Cerrado } \\
\text { Cerradão/ }\end{array}$ & 15,0 & 48,8 & 11,7 & 8,3 & 7,8 & 8,0 & 7,4 \\
\hline $\begin{array}{l}\text { Formações } \\
\text { Florestais }\end{array}$ & 23,8 & 11,5 & 16,4 & 9,4 & 10,0 & 10,8 & 6,4 \\
\hline Pastagem & 41,6 & 1,6 & 31,0 & 12,3 & 13,0 & 21,3 & 11,3 \\
\hline $\begin{array}{l}\text { Pastagem } \\
\text { degradada }\end{array}$ & 6,7 & - & 8,1 & - & - & - & - \\
\hline $\begin{array}{l}\text { Silvicultura } \\
\text { Solo }\end{array}$ & 0,02 & 0,03 & 1,4 & 1,0 & 0,8 & 0,5 & 0,2 \\
\hline $\begin{array}{l}\text { descoberto/ } \\
\text { Área urbana/ } \\
\text { estradas }\end{array}$ & 0,3 & 0,3 & 0,2 & 2,4 & 4,4 & 5,4 & 2,1 \\
\hline
\end{tabular}

Organização: dos autores, 2019.

Nota-se que nas bacias dos rios Doce, Monte Alegre, Verdinho e Verdão localizadas em áreas de topo plano entre os municípios de Rio Verde e Jataí, uma das principais áreas produtoras de grãos do estado de Goiás, mais de $50 \%$ do território é ocupado por cultivos agrícolas. Embora a bacia do Rio Formoso localizese em ambiente com características semelhantes, a presença do Parque Nacional das Emas impede uma ocupação mais ostensiva por agricultura comercial. Já em bacias como dos Rios Bonito e Sucuriú, onde predominam relevo suave ondulado a ondulado, destacam-se as atividades pecuárias.

Observa-se na Tabela 2 que, com exceção do Rio Formoso, que apresenta parte do Parque Nacional das Emas em seu território, todas as demais bacias apresentam áreas de vegetação remanescente em menos de $30 \%$ do território, estando ainda mais restritas em bacias onde predomina o cultivo de grãos. Os padrões espaciais das classes de uso e cobertura da terra podem ser visualizados nas Figuras 3 e 4.

Mesmo que em pequenas proporções, as áreas de Silvicultura foram identificadas em todas as bacias de estudo, considerando que o cultivo de eucalipto tem sido amplamente utilizado para a produção de lenha para secagem de grãos. Chamam atenção ainda a ocorrência de pastagens degradadas, indicando que estas áreas carecem de atenção especial para o planejamento de uso e recuperação.

Com a sobreposição entre as amostras de uso e cobertura da terra e as variáveis de saída do SEBAL (Tabelas 3, 4 e 5), observa-se que os menores valores de albedo da superfície foram identificados sobre áreas de corpos hídricos, e na sequência áreas de silvicultura, cerradão/formações florestais (cobertura vegetal mais densa) e Cerrado (cobertura vegetal mais esparsa). As maiores correlações para a variável albedo foram registradas com a temperatura de superfície (sendo diretamente proporcional) e com o saldo de radiação, calor latente e evapotranspiração (inversamente proporcional), indicando que quanto maior o albedo, menor o saldo de radiação e menor a evapotranspiração. Avaliando o coeficiente de determinação, nota-se que o albedo tem participação em mais de $60 \%$ sobre algumas variáveis, sendo um importante indicador de mudanças ambientais. 


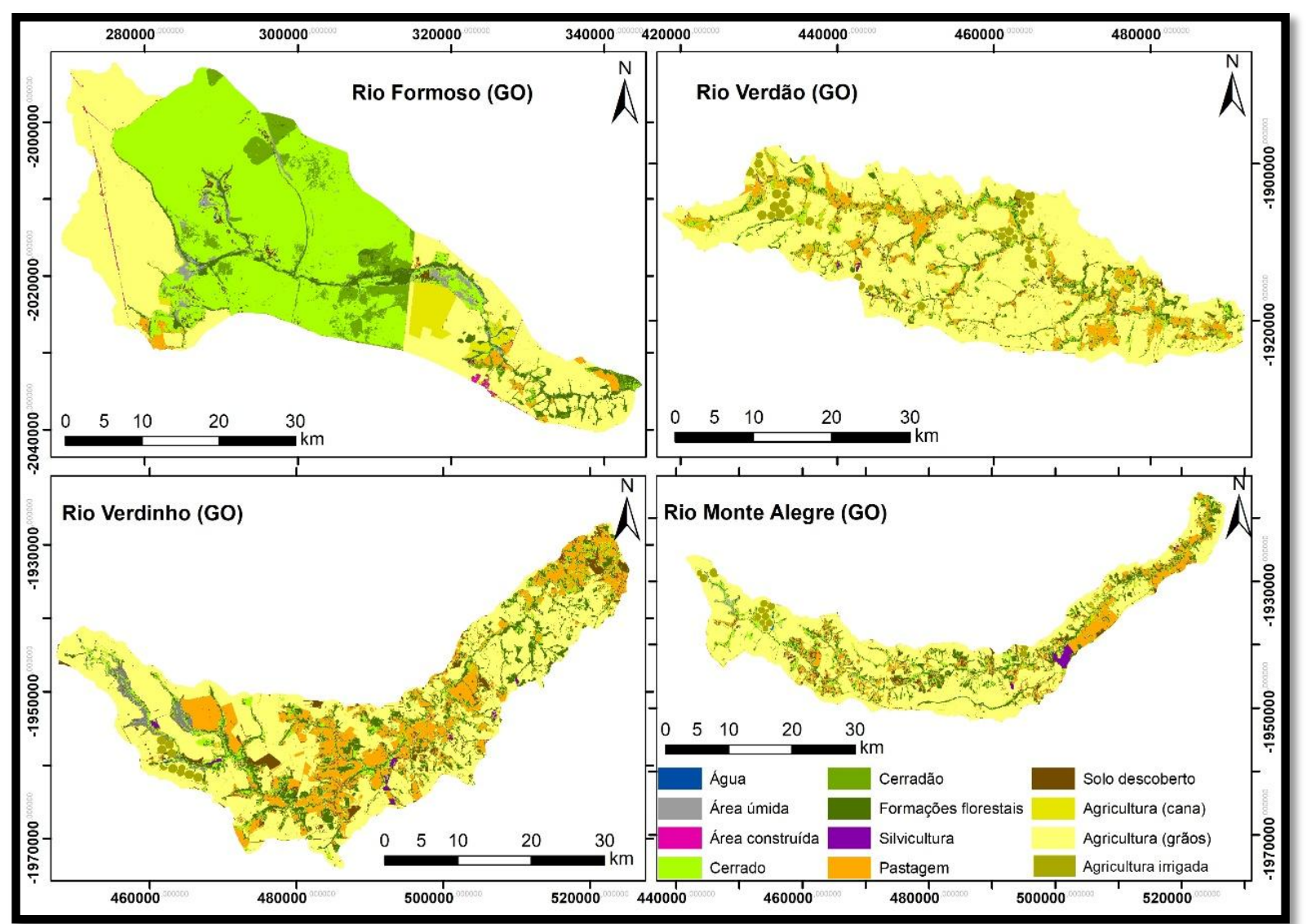

Figura 3: Uso e cobertura da terra nas bacias dos rios Formoso, Verdão, Verdinho e Monte Alegre. Fonte: Imagem OLI/Landsat 8 (6R5G4B em fusão com banda 8), cenas 223/72 e 224/73, Resolução de 15 metros. Disponibilizado pelo USGS, 2019. Organização: dos autores, 2019.

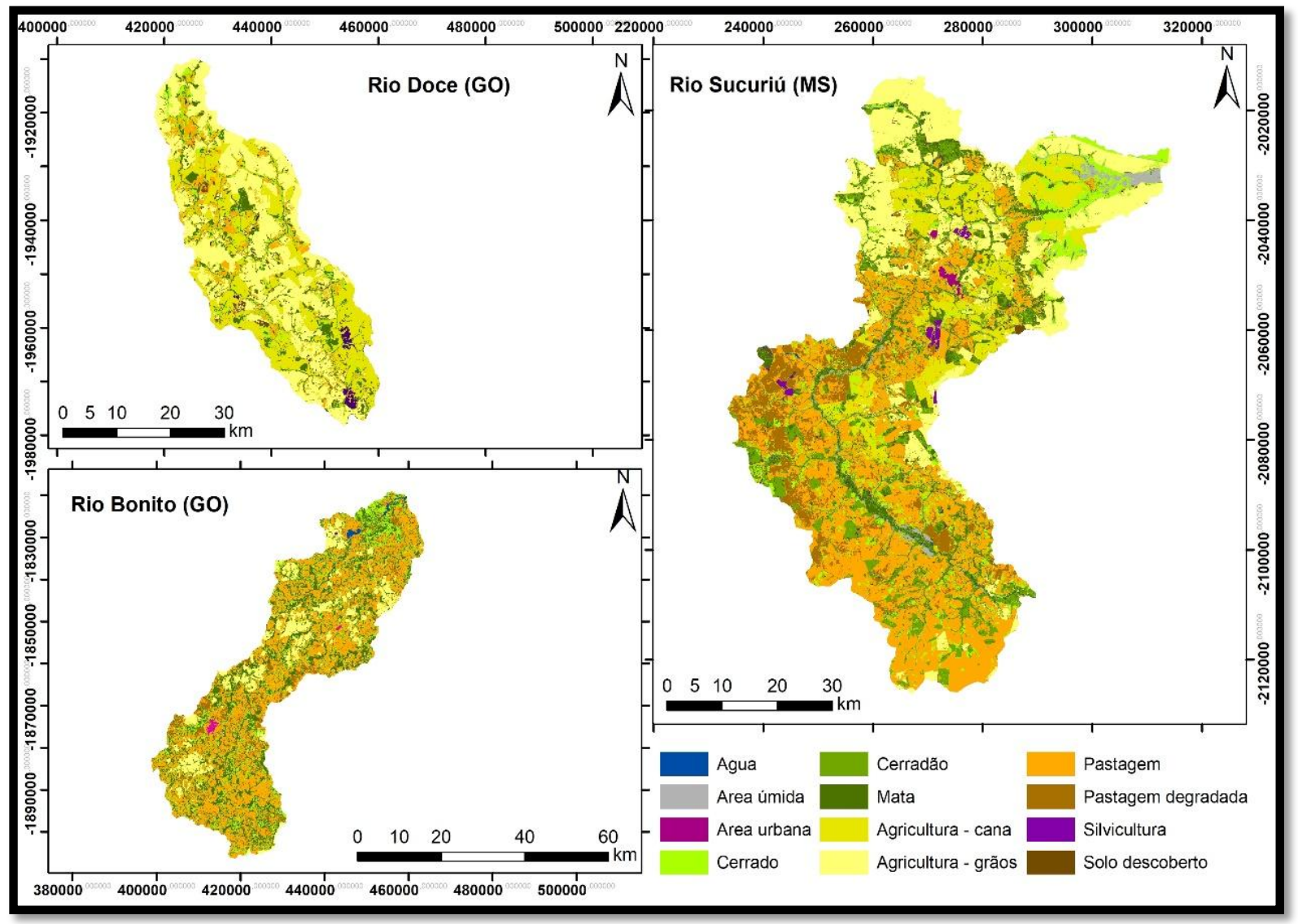

Figura 4: Uso e cobertura da terra nas bacias dos rios Doce, Bonito e Sucuriú - 2019. Fonte: Imagem OLI/Landsat 8 (6R5G4B em fusão com banda 8), cenas 223/72 e 224/73, Resolução de 15 metros. Disponibilizado pelo USGS, 2019. Organização: dos autores, 2019. 
Tabela 3: Médias dos valores de albedo, NDVI, Temperatura de Superfície, Saldo de Radiação, Fluxos de Calor e Evapotranspiração por Uso e cobertura da terra - 2019.

\begin{tabular}{cccccccccc}
\hline Categorias & Albedo & NDVI & TS $(\mathbf{K})$ & $\begin{array}{c}\text { RN } \\
\left(\mathbf{W} / \mathbf{m}^{2}\right)\end{array}$ & $\begin{array}{c}\mathbf{G} \\
\left(\mathbf{W} / \mathbf{m}^{2}\right)\end{array}$ & $\begin{array}{c}\mathbf{H} \\
\left(\mathbf{W} / \mathbf{m}^{2}\right)\end{array}$ & $\begin{array}{c}\text { LE } \\
\left(\mathbf{W} / \mathbf{m}^{2}\right)\end{array}$ & $\begin{array}{c}\text { ETh } \\
(\mathbf{m m} / \mathbf{h})\end{array}$ & $\begin{array}{c}\text { ET24 } \\
(\mathbf{m m} / \mathbf{d i a})\end{array}$ \\
\hline Agricultura (cana) & 0,224 & 0,628 & 307,69 & 556,69 & 87,55 & 174,47 & 289,53 & 0,552 & 5,453 \\
Agricultura (grãos) & 0,227 & 0,661 & 308,33 & 556,34 & 90,97 & 153,44 & 307,03 & 0,595 & 5,813 \\
Agricultura irrigada & 0,220 & 0,752 & 309,23 & 561,57 & 96,81 & 162,40 & 315,39 & 0,558 & 5,507 \\
$\quad$ Água* & 0,108 & $-0,125$ & 304,65 & 637,53 & 84,64 & 26,07 & 480,51 & 0,719 & 7,541 \\
Área úmida & 0,126 & 0,443 & 306,24 & 613,02 & 91,62 & 97,42 & 422,95 & 0,581 & 6,329 \\
$\quad \begin{array}{c}\text { Cerrado } \\
\text { Cerradão/ }\end{array}$ & 0,163 & 0,574 & 307,16 & 599,82 & 91,19 & 123,81 & 372,09 & 0,602 & 6,027 \\
Formações Florestais & 0,153 & 0,710 & 306,23 & 606,76 & 80,73 & 85,39 & 403,20 & 0,663 & 6,120 \\
$\quad$ Pastagem & 0,211 & 0,518 & 308,40 & 559,56 & 94,14 & 128,25 & 287,88 & 0,407 & 4,558 \\
Pastagem degradada & 0,383 & 0,411 & 309,42 & 555,65 & 101,96 & 148,48 & 268,61 & 0,382 & 4,333 \\
$\quad \begin{array}{c}\text { Silvicultura } \\
\text { Solo descoberto/ }\end{array}$ & 0,145 & 0,729 & 306,07 & 605,72 & 77,27 & 107,75 & 425,98 & 0,603 & 6,201 \\
Área urbana/ estradas & 0,213 & 0,373 & 308,84 & 562,17 & 97,61 & 172,031 & 290,31 & 0,408 & 4,895 \\
\hline
\end{tabular}

*Valores referentes à evaporação. Organização: dos autores, 2019.

Tabela 4: Correlação (r) entre as variáveis estimadas pelo modelo SEBAL considerando todas as classes de uso e cobertura da terra -2019 .

\begin{tabular}{|c|c|c|c|c|c|c|c|c|c|}
\hline Categorias & Albedo & NDVI & TS (K) & $\begin{array}{c}\mathbf{R N} \\
\left(\mathbf{W} / \mathbf{m}^{2}\right)\end{array}$ & $\begin{array}{c}\mathbf{G} \\
\left(\mathbf{W} / \mathbf{m}^{2}\right)\end{array}$ & $\mathbf{H}\left(\mathbf{W} / \mathbf{m}^{2}\right)$ & $\begin{array}{c}\text { LE } \\
\left(\mathbf{W} / \mathbf{m}^{2}\right)\end{array}$ & $\begin{array}{c}\text { ETh } \\
(\mathbf{m m} / \mathbf{h})\end{array}$ & $\begin{array}{c}\text { ET24 } \\
(\mathrm{mm} / \mathrm{dia})\end{array}$ \\
\hline Albedo & - & $0,182 n s$ & $0,824 *$ & $-0,788^{*}$ & $0,685^{*}$ & $0,648 *$ & $-0,823^{*}$ & $-0,798^{*}$ & $-0,795 *$ \\
\hline NDVI & $0,182 \mathrm{~ns}$ & - & $0,414 \mathrm{~ns}$ & $0,460 \mathrm{~ns}$ & $0,150 \mathrm{~ns}$ & $0,583 *$ & $0,385 \mathrm{~ns}$ & $0,452 \mathrm{~ns}$ & $-0,535 \mathrm{~ns}$ \\
\hline TS (K) & $0,824 *$ & $0,414 \mathrm{~ns}$ & - & $-0,938^{*}$ & $0,773^{*}$ & $0,880^{*}$ & $-0,945^{*}$ & $-0,951 *$ & $-0,941 *$ \\
\hline $\mathrm{RN}\left(\mathrm{W} / \mathrm{m}^{2}\right)$ & $-0,788^{*}$ & $-0,460 \mathrm{~ns}$ & $-0,938 *$ & - & $-0,607 *$ & $0,917 *$ & $0,982 *$ & $0,981 *$ & $0,988 *$ \\
\hline $\mathrm{G}\left(\mathrm{W} / \mathrm{m}^{2}\right)$ & $0,685^{*}$ & $-0,150 \mathrm{~ns}$ & $0,773 *$ & $-0,607 *$ & - & $0,519 *$ & $-0,679 *$ & $-0,670 *$ & $-0,602 *$ \\
\hline $\mathrm{H}\left(\mathrm{W} / \mathrm{m}^{2}\right)$ & $0,648^{*}$ & $0,583^{*}$ & $0,880^{*}$ & $-0,917^{*}$ & $0,519 \mathrm{~ns}$ & - & $-0,895^{*}$ & $-0,925^{*}$ & $-0,926^{*}$ \\
\hline $\mathrm{LE}\left(\mathrm{W} / \mathrm{m}^{2}\right)$ & $-0,823^{*}$ & $-0,385 n s$ & $-0,945^{*}$ & $0,982 *$ & $-0,679 *$ & $-0,895^{*}$ & - & $0,993 *$ & $0,979 *$ \\
\hline $\operatorname{ETh}(\mathrm{mm} / \mathrm{h})$ & $-0,798^{*}$ & $-0,452 \mathrm{~ns}$ & $-0,951^{*}$ & $0,981 *$ & $-0,670 *$ & $-0,925^{*}$ & $0,993^{*}$ & - & $0,988^{*}$ \\
\hline $\begin{array}{c}\text { ET24 } \\
(\mathrm{mm} / \mathrm{h})\end{array}$ & $-0,795^{*}$ & $-0,535 \mathrm{~ns}$ & $-0,941 *$ & $0,988 *$ & $-0,602 *$ & $-0,926^{*}$ & $0,979 *$ & $0,988 *$ & - \\
\hline
\end{tabular}

A cor azul representa correlação muito forte; verde escuro forte; verde claro moderada; amarelo fraca; vermelho muito fraca ou sem correlação. As variáveis marcadas com (*) apresentam correlação significativa, considerando o valor de t = 2,086 (para 20 graus de liberdade ou 22 amostras); as seguidas por ns indicam correlação não significativa. Organização: dos autores, 2019.

Tabela 5: Coeficiente de determinação $\left(\mathrm{r}^{2}\right)$ entre as variáveis estimadas pelo modelo SEBAL considerando o uso e cobertura da terra -2019 .

\begin{tabular}{|c|c|c|c|c|c|c|c|c|c|}
\hline Categorias & Albedo & NDVI & $\begin{array}{l}\text { TS } \\
(\mathbf{K})\end{array}$ & $\begin{array}{c}\mathbf{R N} \\
\left(\mathbf{W} / \mathbf{m}^{2}\right)\end{array}$ & $\begin{array}{c}\mathbf{G} \\
\left(\mathbf{W} / \mathbf{m}^{2}\right)\end{array}$ & $\begin{array}{c}\mathbf{H} \\
\left(\mathbf{W} / \mathbf{m}^{2}\right)\end{array}$ & $\begin{array}{c}\text { LE } \\
\left(\mathbf{W} / \mathbf{m}^{2}\right)\end{array}$ & $\begin{array}{c}\text { ETh } \\
(\mathbf{m m} / \mathbf{h})\end{array}$ & $\begin{array}{c}\text { ET24 } \\
(\mathrm{mm} / \mathrm{dia})\end{array}$ \\
\hline Albedo & - & 0,033 & 0,679 & 0,621 & 0,469 & 0,420 & 0,678 & 0,636 & 0,633 \\
\hline NDVI & 0,033 & - & 0,172 & 0,212 & 0,022 & 0,340 & 0,148 & 0,205 & 0,286 \\
\hline TS (K) & 0,679 & 0,172 & - & 0,880 & 0,597 & 0,775 & 0,894 & 0,904 & 0,886 \\
\hline $\mathrm{RN}\left(\mathrm{W} / \mathrm{m}^{2}\right)$ & 0,621 & 0,212 & 0,880 & - & 0,369 & 0,840 & 0,963 & 0,963 & 0,975 \\
\hline $\mathrm{G}\left(\mathrm{W} / \mathrm{m}^{2}\right)$ & 0,469 & 0,022 & 0,597 & 0,369 & - & 0,269 & 0,462 & 0,449 & 0,363 \\
\hline $\mathrm{H}\left(\mathrm{W} / \mathrm{m}^{2}\right)$ & 0,420 & 0,340 & 0,775 & 0,840 & 0,269 & - & 0,801 & 0,856 & 0,857 \\
\hline $\mathrm{LE}\left(\mathrm{W} / \mathrm{m}^{2}\right)$ & 0,678 & 0,148 & 0,894 & 0,963 & 0,462 & 0,801 & - & 0,987 & 0,959 \\
\hline $\operatorname{ETh}(\mathrm{mm} / \mathrm{h})$ & 0,636 & 0,205 & 0,904 & 0,963 & 0,449 & 0,856 & 0,987 & - & 0,976 \\
\hline ET24 (mm/h) & 0,633 & 0,286 & 0,886 & 0,975 & 0,363 & 0,857 & 0,959 & 0,976 & - \\
\hline
\end{tabular}

A cor verde escuro representa coeficiente de determinação muito alto; verde claro alto; amarelo mediano; vermelho baixo ou insignificante. Organização: dos autores, 2019.

Oliveira et al. (2018), ao realizar estimativas de albedo a partir de produtos MODIS, destacou que as equações subestimaram o albedo de superfície em $10 \%$ para áreas de cana-de-açúcar e superestimaram em até $21 \%$ para áreas de Cerrado, com um nível de confiança de $95 \%$. Os autores ainda destacaram que os valores de albedo estimados seguiram a série NDVI com aumento na estação chuvosa, diferindo do estudo aqui apresentado onde não identificou-se correlação significativa entre as duas variáveis (Tabela 4). 
Ferreira (2008) observou valores de albedo entre 0,17 e 0,20 em áreas de cana-de-açúcar na bacia do Rio Mogi Guaçu com erro absoluto de 12,21\%. Oliveira et al. (2018) identificaram uma variação sazonal entre 0,15 e 0,20 para áreas de cana-de-açúcar, reforçando que o valor médio de 0,224 identificado nesta pesquisa encontra-se superestimado. Apesar da superestimativa, foi confirmada a alta correlação entre os valores de albedo e os fluxos de calor e evapotranspiração.

Veloso (2014) identificou albedos médios de 0,09 a 0,15 para áreas de Floresta Estacional Decidual e de 0,12 a 0,30 para pastagens e solos descobertos em áreas de Cerrado no Norte de Minas Gerais, valores semelhantes aos identificados nessa pesquisa embora trate-se de uma região com totais pluviométricos mais elevados. Para áreas irrigadas, o autor encontrou variações significativas, de 0,11 a 0,26.

Com relação aos valores de NDVI, nota-se que os valores médios das áreas agrícolas se encontram abaixo da literatura (BEZERRA, 2006; MENDONÇA, 2007; NICÁCIO, 2008; GOMES, 2009; MARTINS, 2015), o que é justificado pelo cálculo do índice em algumas cenas em período de entressafra. Este é um indicativo importante para a correlação não significativa encontrada entre albedo e NDVI, como também acontece para outras variáveis conforme os testes de significância (Tabela 6), apresentando-se moderada apenas para o fluxo de calor sensível e para a evapotranspiração diária, com todos os coeficientes de determinação abaixo de 40\%. Embora não apresente correlações significativas, esta variável é importante para a estimativa de índices utilizados no cálculo de temperatura de superfície, fluxo de calor no solo e fluxo de calor sensível.

Tabela 6: Resultado do teste de significância (t) do Coeficiente de Correlação de Pearson (r) entre as variáveis estimadas pelo modelo SEBAL considerando o uso e cobertura da terra - 2019.

\begin{tabular}{|c|c|c|c|c|c|c|c|c|c|}
\hline Categorias & Albedo & NDVI & TS (K) & $\begin{array}{c}\mathbf{R N} \\
\left(\mathbf{W} / \mathbf{m}^{2}\right)\end{array}$ & $\begin{array}{c}\mathbf{G} \\
\left(\mathbf{W} / \mathbf{m}^{2}\right)\end{array}$ & $\begin{array}{c}\mathbf{H} \\
\left(\mathbf{W} / \mathbf{m}^{2}\right)\end{array}$ & $\begin{array}{c}\text { LE } \\
\left(\mathbf{W} / \mathbf{m}^{2}\right)\end{array}$ & $\begin{array}{c}\text { ETh } \\
(\mathbf{m m} / \mathbf{h})\end{array}$ & $\begin{array}{c}\text { ET24 } \\
(\mathrm{mm} / \mathrm{dia})\end{array}$ \\
\hline Albedo & - & 0,555 & 4,363 & $-3,840$ & 2,821 & 2,552 & $-4,347$ & $-3,972$ & $-3,932$ \\
\hline NDVI & 0,555 & - & 1,364 & $-1,554$ & $-0,455$ & 2,153 & $-1,251$ & $-1,520$ & $-1,900$ \\
\hline TS (K) & 4,363 & 1,364 & - & $-8,118$ & 3,655 & 5,558 & $-8,668$ & $-9,227$ & $-8,342$ \\
\hline $\mathrm{RN}\left(\mathrm{W} / \mathrm{m}^{2}\right)$ & $-3,840$ & $-1,554$ & $-8,118$ & - & $-2,291$ & $-6,897$ & 15,597 & 15,169 & 19,190 \\
\hline $\mathrm{G}\left(\mathrm{W} / \mathrm{m}^{2}\right)$ & 2,821 & $-0,455$ & 3,655 & $-2,291$ & - & 1,822 & $-2,775$ & $-2,708$ & $-2,262$ \\
\hline $\mathrm{H}\left(\mathrm{W} / \mathrm{m}^{2}\right)$ & 2,552 & 2,153 & 5,558 & $-6,897$ & 1,822 & - & $-6,019$ & $-7,303$ & $-7,358$ \\
\hline $\mathrm{LE}\left(\mathrm{W} / \mathrm{m}^{2}\right)$ & $-4,347$ & $-1,251$ & $-8,668$ & 15,597 & $-2,775$ & $-6,019$ & - & 25,221 & 14,407 \\
\hline ETh $(\mathrm{mm} / \mathrm{h})$ & $-3,972$ & $-1,520$ & $-9,227$ & 15,169 & $-2,708$ & $-7,303$ & 25,221 & - & 19,190 \\
\hline ET24 (mm/h) & $-3,932$ & $-1,900$ & $-8,342$ & 19,190 & $-2,262$ & $-7,358$ & 14,407 & 19,190 & - \\
\hline
\end{tabular}

Considerando o universo de 22 pares de variáveis com 20 graus de liberdade (n-2), o valor tabelado para o teste T de student (T crítico) é de $\pm 2,086$. Valores superiores a este indicam rejeição da hipótese de nulidade e confirmação da hipótese científica (significância da correlação de Pearson). Organização: dos autores, 2019.

Veloso (2014) indicou variações de NDVI entre 0,256 (período seco) e 0,707 (período chuvoso) para áreas de Cerrado, reforçando a relação deste índice com a sazonalidade da região, com médias de 0,506. Já para as pastagens e solos descobertos o autor identificou variações de 0,201 a 0,609, indicando uma dinâmica muito semelhante às áreas de Cerrado com vegetação menos densa.

A temperatura de superfície apresentou correlações forte e muito forte (significativas) com a maioria das variáveis (com exceção do NDVI), indicando ser o principal parâmetro biofísico na determinação do saldo de radiação e dos fluxos de calor e evapotranspiração. Apresenta-se diretamente proporcional ao albedo, fluxo de calor no solo e fluxo de calor sensível, sendo um importante indicativo de que a mudança das categorias de uso e cobertura da terra (albedo) aumentam significativamente a temperatura, com coeficiente de determinação de $68 \%$. É inversamente proporcional ao saldo de radiação, calor latente e evapotranspiração (correlação muito forte), com coeficientes de determinação próximos a 90\% (Tabela 5), indicando que em altas temperaturas a evapotranspiração tende a ser menor.

Ferreira (2008), encontrou variações de temperatura de superfície entre $299 \mathrm{~K}$ e $305 \mathrm{~K}$ sobre áreas de Cerrado e de 290 K a 310 K sobre áreas de cana-de-açúcar na bacia do Rio Mogi Guaçu, indicando que superfícies com vegetação natural tendem a apresentar menores amplitudes térmicas. Esta variação se deve, sobretudo, aos diferentes períodos de desenvolvimento da cultura. Veloso (2014) calculou temperaturas médias variando de 294,6 K a 306,7 K para áreas de Cerrado no Norte de Minas Gerais, semelhantes aos valores encontrados para as sete bacias em estudo e aos apresentados por Ferreira (2008).

Considerando o saldo de radiação em superfície, resultado da primeira etapa do SEBAL, nota-se que este apresenta correlação forte e muito forte com a maioria das variáveis, com exceção de NDVI e fluxo de calor no solo, com coeficiente de determinação acima de $80 \%$ com temperatura de superfície e fluxo de calor 
sensível, e acima de $96 \%$ com calor latente e evapotranspiração. Como são variáveis interdependentes, estes valores indicam o bom desempenho do modelo na estimativa. Apresenta-se diretamente proporcional aos valores de Calor Latente e evapotranspiração, indicando que quanto maior o saldo de radiação, maiores os volumes de evapotranspiração, ressaltando a importância das superfícies vegetadas e de baixo albedo neste processo.

Utilizando o SEBAL, Veloso (2014) encontrou variações entre 445,28 W/m² e 689,83 W/m² para o Saldo de Radiação em áreas irrigadas do Norte de Minas Gerais (média de 567,61 W/m²), valores próximos aos identificados nesta pesquisa. Ruhoff et al. (2012) ao comparar o saldo de radiação estimado pelo SEBAL e o mensurado por instrumentos em estações identificou um coeficiente de determinação de 0,86 para áreas de Cerrado e de 0,85 para áreas cultivadas com cana-de-açúcar, apontando uma tendência do modelo em subestimar os valores.

É importante observar que, apesar de envolver as variáveis de albedo, temperatura, NDVI e Saldo de Radiação em seu cálculo, o fluxo de calor no solo apresentou correlação forte apenas com a temperatura de superfície, sendo moderado para os demais. Além disso, a correlação entre fluxo de calor no solo e fluxo de calor sensível não demonstrou significância, indicando que esta é uma estimativa que carece de mais estudos para regiões tropicais, inclusive com apoio instrumental em campo. Já o coeficiente de determinação foi inferior a $60 \%$ para todas as variáveis, o que estatisticamente é um indicativo de que essa etapa do modelo necessita de adaptações para chegar a valores mais exatos, apontando como alternativa o uso de instrumentos para calibração dos valores em campo. Ruhoff (2011) identificou coeficientes de determinação medianos quando comparados os valores de fluxo de calor no solo estimados aos mensurados por instrumentos, de 0,44 e 0,56 para áreas de Cerrado e áreas cultivadas com cana-de-açúcar, respectivamente.

Com relação ao fluxo de calor sensível, considerada a etapa mais complexa de implementação do SEBAL, foi observada correlação forte positiva com a temperatura de superfície e muito forte negativa com saldo de radiação, calor latente e evapotranspiração e coeficientes de determinação superiores a $80 \%$ para estas variáveis. Estes valores indicam o acerto de estimativa da variável, apesar de sua complexidade, e que valores mais elevados de fluxo de calor sensível indicam menores volumes de evapotranspiração, servindo também como indicativo dos efeitos das mudanças ambientais sobre o ciclo da água no ambiente. Ruhoff (2011) identificou coeficiente de determinação de moderado a alto ao comparar os valores de fluxo de calor sensível estimados aos medidos em estação micrometeorológica, com 0,52 para áreas de Cerrado e 0,60 para cultivos de cana-de-açúcar.

Considerado o saldo de energia restante de todo o processo para gerar a evapotranspiração, o calor latente apresentou correlação muito forte com as demais variáveis (com exceção do NDVI), indicando os bons resultados do modelo com coeficientes de determinação acima de $90 \%$, chegando a $99 \%$ e $96 \%$ para a evapotranspiração horária e diária, respectivamente.

Já a correlação entre a evapotranspiração instantânea (ETh) e evapotranspiração diária (ET24), como esperado, apresentou-se muito forte positiva e com coeficiente de determinação de $98 \%$ visto que a ETr24 é calculada a partir da ETrh. Dificilmente o coeficiente chegaria a 1, considerando que utiliza uma fração entre ETrh e evapotranspiração de referência, que podem apresentar nessa escala erro de até $13 \%$. $\mathrm{O} \mathrm{r}^{2}$ de $98 \%$ indica grande qualidade para os dados produzidos considerando as categorias de uso e cobertura da terra. Em seu estudo, Ruhoff et al. (2012) apresentaram coeficiente de determinação de $88 \%$ ao comparar os valores de Evapotranspiração Diária estimados pelo SEBAL e pelo modelo hidrológico MGB-IPH, apresentando erros compatíveis aos encontrados neste estudo.

\section{Considerações finais}

A partir dos resultados apresentados, considera-se que o SEBAL apresenta valores mais significativos de correlação e coeficiente de determinação quando consideradas as categorias de uso e cobertura da terra do que aqueles apresentados no processo de validação com as variáveis registradas nas estações meteorológicas do INMET. Estes números ressaltam a importância e aplicabilidade do modelo para estimativa de evapotranspiração em áreas mais extensas, com grande diversidade de ambientes naturais e antrópicos e com poucos dados de monitoramento de campo.

É perceptível o papel importante dos parâmetros albedo e temperatura de superfície sobre o balanço de radiação, fluxos de calor e evapotranspiração, indicando que as mudanças das relações de uso e cobertura da terra afetam diretamente o ciclo da água no ambiente. Além disso, os resultados do processamento demonstraram fragilidades com relação aos dados estimados de NDVI, indicando a necessidade de estudos 
mais específicos sobre este tema considerando a sazonalidade climática do Cerrado e os períodos de entressafra e de vazio sanitário nas áreas produtoras de grãos.

O aumento do albedo de superfície provocado pela conversão de áreas com vegetação natural em zonas de produção agropecuária também se reflete no aumento da temperatura de superfície e diminuição dos volumes de evapotranspiração. Como se trata de um ciclo, acaba por interferir na disponibilidade hídrica para consumo, visto que altera o regime de vazão dos canais superficiais. Indica-se, ainda, que estas mudanças ambientais possam ser responsáveis pela alteração no regime de chuvas em escala local/regional, seja em volume e/ou intensidade, assim como no ciclo anual das vazões.

\section{Agradecimentos}

O estudo apresenta continuidade à tese de doutorado do primeiro autor intitulada "Uso de dados do sensor MODIS/AQUA e do algoritmo SEBAL para estimativa da evapotranspiração real na bacia do Rio Paranaíba". Agradeço ao Programa de Pós-Graduação em Geografia da Universidade Federal de Uberlândia e ao Prof. Dr. Roberto Rosa pela orientação. O segundo autor agradece a Bolsa de Produtividade e Pesquisa (PQ) do CNPq por meio do processo 304973/2017-3. Esta pesquisa foi realizada com apoio do Programa Nacional de Cooperação Acadêmica (PROCAD) da Coordenação de Aperfeiçoamento de Pessoal de Nível Superior - CAPES/Brasil - Edital CAPES 071/2013 - Processo número 88881.068465/2014-01.

\section{Referências}

Ab'SABER, Aziz N. Os Domínios de natureza no Brasil: potencialidades paisagísticas. São Paulo: Ateliê, 2003.

AGÊNCIA NACIONAL DE ÁGUAS (ANA). Hidroweb - Sistema de Informações Hidrológicas. Disponível em: < http://www.snirh.gov.br/hidroweb/publico/ medicoes_historicas_abas.jsf\#>. Acesso em 15 de janeiro de 2020.

ALLEN, R. G.; PEREIRA, L. S.; RAES, D.; SMITH, M. Crop evapotranspiration - Guidelines for computing crop water requirements. In: FAO Irrigation and drainage paper 56. FAO, v.300, n.9, p. 1-297, 1998.

ALLEN, R. G. et al. SEBAL (Surface Energy Balance Algorithms for Land) advanced training and users manual - Idaho implementation. Idaho: Idaho University, USA, 2002. 98p.

ALLEN, R. G. et al. Satellite-Based Energy Balance for Mapping Evapotranspiration with Internalized Calibration (METRIC) - Model. In: Journal of irrigation and drainage engineering, v. 133, n.04, p.380394, 2007. https://doi.org/10.1061/(ASCE)0733-9437(2007)133:4(380)

ARIZA, A. Descripción y Corrección de Productos Landsat 8 LDCM (Landsat Data Continuity Mission). Bogotá: Instituto Geográfico Agustín Codazzi, 2013. 46p.

BASTIAANSSEN, W. G. M., Regionalization of surface flux densities and moisture indicators in composite terrain. 1995. 273p. Tese (Ph.D.) - Wageningem Agricultural University, Wageningen, Netherlands, 1995.

BASTIAANSSEN, W. G. M. et al. A remote sensing surface energy balance algorithm for land (SEBAL): 2. Validation. Journal of Hydrology, v. 212 - 213, p. 213 - 229. 1998. https://doi.org/10.1016/S00221694(98)00254-6

BEZERRA, B. G. Balanço de energia e evapotranspiração em áreas com diferentes tipos de cobertura de solo no Cariri cearense através do algoritmo SEBAL. 2006. 147p. Dissertação (Mestrado em Meteorologia) - Unidade Acadêmica de Ciências Atmosféricas, Universidade Federal de Campina Grande, Campina Grande, Paraíba, 2006.

COHEN, J. A Coefficient of Agreement for Nominal Scales. Educational and Psychological Measurement. v.20 (1960), p. 37 - 46. 1960. https://doi.org/10.1177/001316446002000104 
DUBREUIL, V. et al. Os tipos de climas anuais no Brasil : uma aplicação da classificação de Köppen de 1961 a 2015. Confins [online], v. 37, n.37, 2018. https://doi.org/10.4000/confins. 15738

ENVIRONMENTAL SYSTEMS RESEARCH INSTITUTE (ESRI) INC. ArcGis versão 10.6.1. EUA: Environmental Systems Research Institute, 2018.

FERREIRA, R. C. Calibração do SEBAL/METRIC e mapeamento do saldo de radiação com imagens Landsat 5 - TM e modelo de elevação digital. 2008. 93p. Dissertação (Mestrado em Meteorologia) Unidade Acadêmica de Ciências Atmosféricas, Universidade Federal de Campina Grande, Campina Grande, Paraíba, 2008.

FIGUEIREDO, G. C.; VIEIRA, C. A. O. Estudo do comportamento dos índices de Exatidão Global, Kappa e Tau, comumente usados para avaliar a classificação de imagens do sensoriamento remoto. In: Simpósio Brasileiro de Sensoriamento Remoto, 13. 2007. Florianópolis. Anais... Florianópolis: Inpe, 2007 p. $5755-$ 5762 .

GOMES, H. B. Balanço de Radiação e energia em áreas de cultivo de cana-de-açúcar e Cerrado no estado de São Paulo mediante imagens orbitais. 2009. 108p. Tese (Doutorado em Meteorologia) Unidade Acadêmica de Ciências Atmosféricas, Universidade Federal de Campina Grande, Campina Grande, Paraíba, 2009.

INSTITUTO NACIONAL DE METEOROLOGIA (INMET) - BDMEP - Banco de Dados Meteorológicos para Ensino e Pesquisa. Disponível em <http://www.inmet.gov.br/projetos/rede/pesquisa/> Acesso em 10 out. 2019.

INSTITUTO NACIONAL DE METEOROLOGIA (INMET) - Rede de estações automáticas. Disponível em < http://www.inmet.gov.br/portal/index.php?r=estacoes/ estacoesAutomaticas> Acesso em 10 out. 2019.

INSTITUTO NACIONAL DE PESQUISAS ESPACIAIS (INPE). Projeto PRODES de monitoramento do Cerrado brasileiro por satélite. Disponível em: http://terrabrasilis.dpi.inpe.br/app/dashboard/deforestation/biomes/cerrado/increments>. Acesso em 15 de Janeiro de 2020.

LANDIS, J. R.; KOCH, G. G. The measurement of observer agreement for categorical data. Biometrics, v.33, n.1, p.159-174, mar. 1977. https://doi.org/10.2307/2529310

MAPBIOMAS. Disponível em: < https://mapbiomas.org/>. Acesso em 15 de Janeiro de 2020.

MARIANO, Z. F. A importância da variável climática na produtividade de soja no sudoeste de Goiás. 2005. 253p. Tese (Doutorado em Geografia) - Programa de Pós-Graduação em Geografia, Universidade Estadual de São Paulo, Rio Claro, São Paulo, 2005.

MARTINS, A. P. Uso de dados do sensor MODIS/AQUA e do algoritmo SEBAL para estimativa da evapotranspiração real na bacia do Rio Paranaíba. 2015. 150p. Tese (Doutorado em Geografia) Programa de Pós-Graduação em Geografia, Universidade Federal de Uberlândia, Uberlândia, Minas Gerais, 2015.

MARTINS, A. P.; SCOPEL, I.; SOUSA, M. S.; PEIXINHO, D.M. Uso da terra e cobertura vegetal de 1985 a 2015 no Sudoeste de Goiás e relações com o meio físico. In: PEIXINHO, D.; SOUSA, M.S. (Orgs.). Reconfiguração do Cerrado: uso, conflitos e impactos ambientais. Goiânia, GO: Gráfica UFG, 2016. p. 11 34.

MENDONÇA, J. C. Estimação da evapotranspiração regional utilizando imagens digitais orbitais na região Norte Fluminense, RJ. 2007. 167p. Tese (Doutorado em Produção Vegetal) - Centro de Ciências e Tecnologias Agropecuárias, Universidade Estadual do Norte Fluminense, Campos dos Goytacazes, Rio de Janeiro, 2007.

MENDONÇA, J. C. et al. Aplicação do algoritmo SEBAL e imagens MODIS para estimativa do fluxo de calor no solo $(\mathrm{G})$ na região Norte Fluminense, RJ, Brasil. In: SBSR, SIMPÓSIO BRASILEIRO DE 
SENSORIAMENTO REMOTO, 14, 2009, Natal/RN. Anais do XIV Simpósio Brasileiro de Sensoriamento Remoto. Natal: INPE, 2009. p.293-300.

MING, T. C.; LIU, W. T. H. Estimativa de albedo, temperatura e NDVI do estado de São Paulo através de dados AVHRR do satélite NOAA. In: CBM, CONGRESSO BRASILEIRO DE METEOROLOGIA, 11, 2000. Rio de Janeiro/RJ. Anais do XI Congresso Brasileiro de Meteorologia. Rio de Janeiro, 2000. p. 3843-3850.

MOREIRA, L. C. J. et al. Variabilidade local e regional da evapotranspiração estimada pelo algoritmo SEBAL. Engenharia Agrícola, Jaboticabal, v30, n06, Nov/dez2010. p.1148-1159. 2010. https://doi.org/10.1590/S0100-69162010000600015

NICÁCIO, R. M. Evapotranspiração real e umidade do solo usando dados de sensores orbitais e a metodologia SEBAL na bacia do Rio São Francisco. 2008. 337p. Tese (Doutorado em Engenharia Civil) Programa de Pós-Graduação em Engenharia Civil, Universidade Federal do Rio de Janeiro, 2008.

OLIVEIRA, B. S. et al. Improved Albedo Estimates Implemented in the METRIC Model for Modeling Energy Balance Fluxes and Evapotranspiration over Agricultural and Natural Areas in the Brazilian Cerrado.

Remote Sensing, 10, p.1-27. 2018. https://doi.org/10.3390/rs10081181

PESSÔA, V.L.S. Ação do estado e as transformações agrárias no Cerrado das zonas de Paracatu e Alto Paranaíba. 1988. 239p. Tese (Doutorado em Geografia) - Universidade Estadual Paulista, Rio Claro, São Paulo, 1988.

ROGERSON, P. A. Métodos estatísticos para Geografia: um guia para o estudante. $3^{\text {a }}$ ed. Porto Alegre: Bookman, 2012. 348 p.

RUHOFF, A. L. Sensoriamento Remoto aplicado à estimativa de evapotranspiração em biomas tropicais. 2011. 180p. Tese (Doutorado em Recursos Hídricos e Saneamento Ambiental) - Instituto de Pesquisas Hidráulicas, Universidade Federal do Rio Grande do Sul, Porto Alegre, Rio Grande do Sul, 2011.

RUHOFF, A. L. et al. A MODIS-Based Energy Balance to Estimate Evapotranspiration for Clear-Sky Days in Brazilian Tropical Savannas. Remote Sensing, 4, p.703-725. 2012. https://doi.org/10.3390/rs4030703

SILVA, C. A. Precipitações no Cerrado: análise da variabilidade pluviométrica e influência do fenômeno El Niño Oscilação Sul. 2018. 190p. Tese (Doutorado em Geografia) - Programa de PósGraduação em Geografia, Universidade de Brasília, Brasília, Distrito Federal, 2018.

UNITED STATES GEOLOGICAL SURVEY (USGS). Download de imagens Landsat, SRTM e Sentinel. Disponível em: < https://earthexplorer.usgs.gov/>. Acesso em 15 de setembro de 2019

VELOSO, G. A. Análise espaço temporal dos componentes do balanço de radiação, energia e evapotranspiração usando técnicas de sensoriamento remoto em áreas irrigadas do Projeto Jaíba/MG. 2014. 150p. Dissertação (Mestrado em Geografia) - Programa de Pós-Graduação em Geografia, Universidade Federal de Uberlândia, Uberlândia, Minas Gerais, 2014.

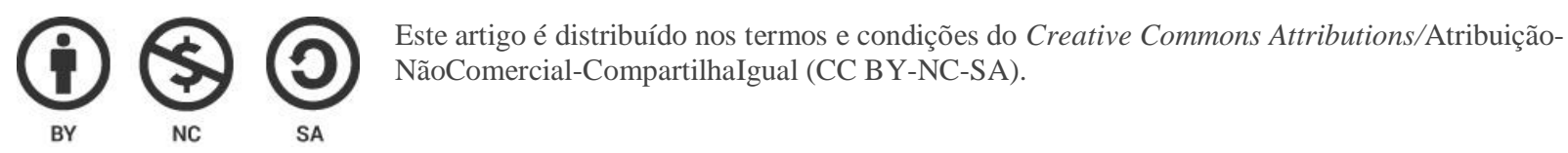

